\title{
Application of magnetorheological fluids in the design of a leg prosthesis with active damping
}

\author{
Oscar Arteaga ${ }^{1, *}$, Alex Cevallos ${ }^{1}$, Maria I. Erazo ${ }^{1}$, Klever D. Morales ${ }^{1}$, Daniel Tenezaca B. ${ }^{1}$, and Edison Argüello M. ${ }^{1}$
}

${ }^{1}$ Departamento de Ciencias de la Energía y Mecánica, Universidad de las Fuerzas Armadas ESPE, Sangolquí, Ecuador.

\begin{abstract}
The article is about of research of the behavior of magnetorheological materials (MR), later it will be implemented in a prototype leg prosthesis with active damping for people who have suffered amputations in lower extremities, which considers the use of an actuator with Magnetorheological Fluids (MRF) $L O R D M R F-140 C G$, whose control is based on the adjustment of the magnetic field applied to the MRF using in its design the main parameters of anatomy and biomechanics of the foot-leg system, so that the force applied in the course of the gait cycle it can be absorbed by the prosthesis, reducing the impact on the user's column thus allowing the prosthesis to be subjected to tests for emulation in different positions according to the applied load.
\end{abstract}

\section{Introduction}

The amputation of a lower extremity is a problem that affects a specific number of people in the world, who when exposed to a totally different environment, can develop feelings such as distrust and insecurity until they adapt to the imminent need to use a prosthesis that allows them to balance their rhythm of life and re-establish the way they have lived up to that moment. [1]. Nowadays the technological advance of the prosthesis has allowed the patient to overcome the inconveniences presented in everyday life [2,3]

In order to minimize the impact caused by the absence of the lower extremity, Mechatronics as a synergistic effect of the integration of different disciplines in the design of a multidisciplinary system [4], it has developed a significant revolution in fields such as assistance robotics and rehabilitation of the lower extremities [5]. In Ecuador from 2007 to 2013 there are around 875 cases of traumatic amputations of the lower limb, and this number is expected to increase [6].

The willingness of patients to use a leg prosthesis with active damping allows drastically improve their mobility and enables them to participate in activities of daily living improving their quality of life $[7,8,9]$, to this is added the natural movement and dexterity that a prosthesis provides. [3]

With the aim of avoiding the damages represented by the use of a prosthesis, this prosthesis is based on the principle of mass-spring-cushioned, the damping generated by a MRF which is a material that can change viscosity according to the applied magnetic field, can get to form a thick mass, all this without changing its volume. [10]

This article has 5 sections, including the Introduction. Section 2 describes the mechanical characteristics of the MRF. Section 3 describes the design of the shock absorber. Section 4 describes the tests and results of the prosthesis. Finally, the Conclusions are presented in Section 5. In future works it is expected to publish the results in the tests with real patients.

\section{Fluid MR}

The experimental procedure for the magnetorheological characterization of the fluid MRF-140CG of LORD is established. This procedure involves the use of the rotational rheometer MRC-501 Anton Paar Physica together with the cell MRD-70/1T coupled [11]. Together, a thermostatic bath Julabo F-25 is made to maintain a temperature of $20^{\circ} \mathrm{C}$, the results obtained for a magnetic field of $0 \mathrm{~T}$ are shown in the figure 1 .

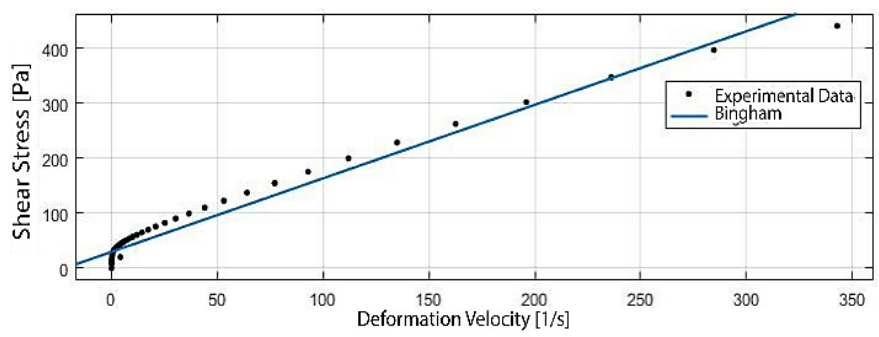

Fig. 1. Shear stress vs. strain rate at $20{ }^{\circ} \mathrm{C}$

Applying the Bingham model for MRF, the shear stress equation is obtained $(\tau)$, depending of the strain rate $(\dot{\gamma})$, where the slope (1.338 Pa.s) represents the plastic viscosity $(\eta)$ independent of the magnetic field.

$$
\tau=29.8+1.338 \dot{\gamma}
$$

Similarly, the equation that predicts the MRF shear threshold for a magnetic field was obtained $(\dot{\gamma})$ of $600 \mathrm{mT}$, and strain rate of $3501 / \mathrm{s}$, shown in the figure 2 , from which a value of $\tau_{y}(H)$ is obtained and it is $35117.639 \mathrm{~Pa}$.

\footnotetext{
*Corresponding author: obarteaga@espe.edu.ec
} 


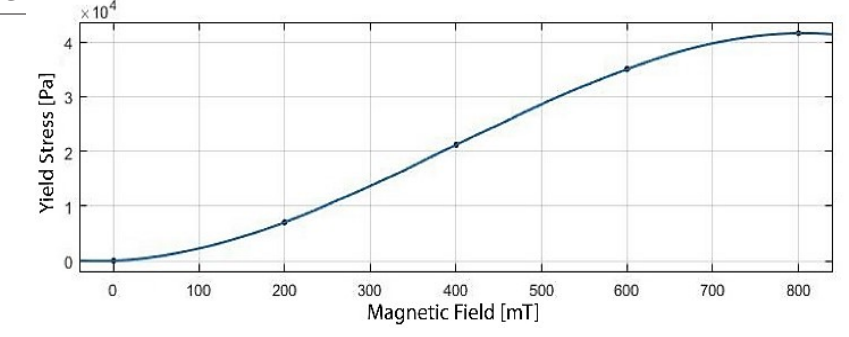

Fig. 2. Yield Stress Vs Magnetic Field at $20{ }^{\circ} \mathrm{C}$

\section{Shock absorber design}

\subsection{Design Parameters}

Ecuador is a multi-ethnic and pluricultural country. The size and weight of its inhabitants vary according to genetics and nutrition, taking as initial parameters, an average height of the Ecuadorian man of $1.68 m-1.70 m$ and a total body mass of $70 \mathrm{~kg}[12]$.

According to the parameters of the Dempster and Clauser model, the weight of the leg represents $4.3 \%$ of the total weight of the body [13]. Therefore, the critical force that the prosthesis must withstand in critical operating conditions is $3432.1 \mathrm{~N}$ generated by the mass of the entire body and supported by the legs. For study reasons, half of the impact force is considered to multiply it by a load factor of 1.2, resulting in $2059.26 \mathrm{~N}$ which represents the design strength $\left(F_{d}\right)$.

It is considered that the MR damper works in valve mode [18], shown in the figure 3.

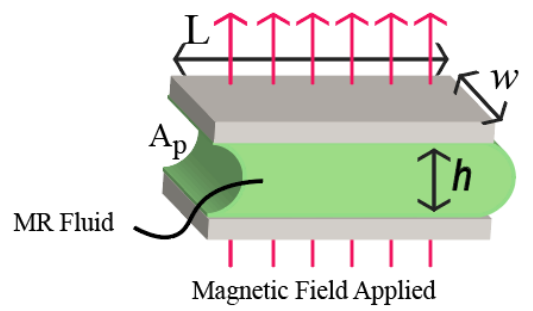

Fig. 3. Mode of operation of the MR fluid as valve.

Where, $w$ is the width of the magnetic pole $w=$ $\pi\left(D_{p}+h\right), \mathrm{L}$ is a length of magnetic pole and $h$ is the angular pipeline or gap.

In the design of the shock absorber is based on the following established parameters, whose nomenclature is shown in the figure 4.

$\begin{array}{lc}\text { Damping stroke } & c_{a}=0.020 \mathrm{~m} \\ \text { Outer diameter of the cylinder } & D_{c}=0.0421 \mathrm{~m} \\ \text { Thickness of the cylinder liner } & t_{w}=0.006 \mathrm{~m} \\ \text { External diameter } & D_{e}=0.0301 \mathrm{~m} \\ \text { Cylinder sleeve length } & L=0.01 \mathrm{~m}\end{array}$

Maximum diameter of the magnetic pole $D_{n}=0.022 \mathrm{~m}$

Coil length

$L_{b}=0.01 \mathrm{~m}$

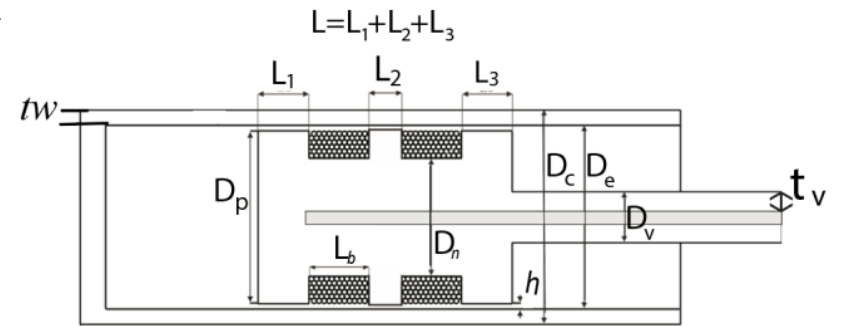

Fig. 4. Scheme MR damper.

To calculate the average speed of the piston requires the damping time that results $40 \%$ of the total duration of the human gait cycle [14], which is $\Delta t_{c}=0.456 \mathrm{~s}$, which is the time when all the weight of the body is supported by one leg.

Then, the average piston velocity that is calculated:

$$
V_{a}=\frac{c_{a}}{\Delta t_{c}}=0.044 \frac{\mathrm{m}}{\mathrm{s}}
$$

\subsection{Dimensioning of the MR shock absorber}

The controllable force and the dynamic range are two of the most important parameters in the evaluation of the overall performance of the MR damper, [15] and for their analysis are decomposed into:

$F_{\tau(H)}$ : Controllable force, dependent on a shear stress, $\tau_{y}(H) .[2]$

$$
F_{\tau(H)}=c \frac{\tau_{y}(H) L A_{P}}{h} \operatorname{sgn}\left(V_{a}\right)
$$

$F_{u c}$ : Uncontrollable force, which is equal to the sum of the frictional force and the plastic viscosity force.

$$
F_{u c}=2 F_{n}=343.35 \mathrm{~N}
$$

$F_{n}$ : Plastic viscosity force.

$$
\begin{gathered}
F_{\eta}=\left(1+\frac{w h \cdot V_{a}}{2 \cdot Q}\right) \frac{12 \cdot \eta \cdot Q \cdot L \cdot A_{P}}{w \cdot h^{3}} \\
c \approx 2.07+\frac{1}{(1+0.4 \tau)}
\end{gathered}
$$

Friction force $F_{f}$, is of the same magnitude as the plastic viscosity force $F_{n}$. [18]. Where the value of $c$ oscillates between 2.07 and 3.07 calculated by the equation $7, Q$ is the flow that is equal to $A_{p} . V_{a}=\pi\left(D_{e}-2 h\right)^{2} * \frac{V_{a}}{4}=$ $2.8743 \times 10^{-5} \frac{m^{3}}{s}$ y $A_{P}$ is the cross section of the piston that is equal to $\pi\left(D_{e}-2 h\right)^{2} / 4=6.5325 * 10^{-4} \mathrm{~m}^{2}$. [15] and with the previous equations the angular duct is calculated that is equal to $0.0063 \mathrm{~m}$.

The dynamic range (D) is defined as the ratio between the strength of the shock absorber and the uncontrollable force $F_{u c}$ [15].

$$
D=\frac{F}{F_{u c}}=1+\frac{F_{\tau}}{F_{n}+F_{f}}
$$


From where it is determined that the value of the dynamic range is 7 , taking into account that this force is equal to the contact force of the ground when a person is standing upright, in the resting state is equal to half the body weight, [15] obtaining that the controllable force is:

$$
F_{\tau}=F_{d}=2059.26[N]
$$

\subsection{Shock absorber cylinder design}

It is necessary to consider the pressure that is generated internally in the cylinder to determine the thickness of the cylinder liner, the same that will be made of steel AISI 1050 $\mathrm{HR}$, the thickness of the cylinder liner is determined $t$ [17], with the following equation:

$$
\sigma=\frac{\Delta P * r}{2 * t}
$$

Where, the inner radius of the cylinder liner $r=$ $0.01505 \mathrm{~m}$ and maximum yield stress $\sigma=338 \mathrm{MPa}$, resulting from the previous equation the thickness $t_{w}=$ $0.0361 \mathrm{~mm}, 112 / 5000$

that is the minimum to withstand the pressure generated, so for the design is assigned a wall thickness of $2 \mathrm{~mm}$.

For the design of the stem take into account that it must be able to transmit all the force without buckling or fracture, also that it must be hollow to give space to the cables that excite the coil, as shown in the figure 4.

$t_{v}:$ wall thickness of the stem $=0.001 \mathrm{~m}$

$L_{v}:$ stem length $=0.06 \mathrm{~m}$

$D_{v}:$ diameter of the stem $=0.01 \mathrm{~m}$

\subsection{Design of the shock absorber stem}

The stem is subjected to an analysis per column, in which the critical load is determined as a short column, this analysis is performed with the equation of J. B. Johnson [16], con $S_{y}=$ $276 \times 10^{6} P a, E=207 \times 10^{9} P a$ y $A=\pi\left(D_{v}{ }^{2}-\left(D_{v}-2 t_{v}\right)^{2}\right) /$ 4.

$$
\begin{gathered}
P_{c r}=A * S_{y}\left[1-\frac{S_{y}\left(\frac{L_{e}}{r}\right)^{2}}{4 \pi^{2} E}\right]=7744 \mathrm{~N} \\
P_{a}=\frac{P_{c r}}{N}=2581 \mathrm{~N}
\end{gathered}
$$

Where, $P_{c r}$ is the critical load of the column, $A$ the crosssectional area of the hollow stem, $P_{a}$ is the allowable load for the hollow stem and $\mathrm{N}$ is a safety factor that is equal to 3 for this type of design. [18]

The admissible load is $2581 \mathrm{~N}$ which is greater than 2059.26 $\mathrm{N}$ which is the maximum load produced in the cylinder, therefore, it is concluded that the design is safe.

\subsection{Control Circuit Design}

The design of the control circuit consists of a microcontroller with the function of operating the electromagnet, which in turn generates the magnetic field, with the help of a PWM signal, which will be modulated according to the information received by a load cell, shown in the figure 5 .

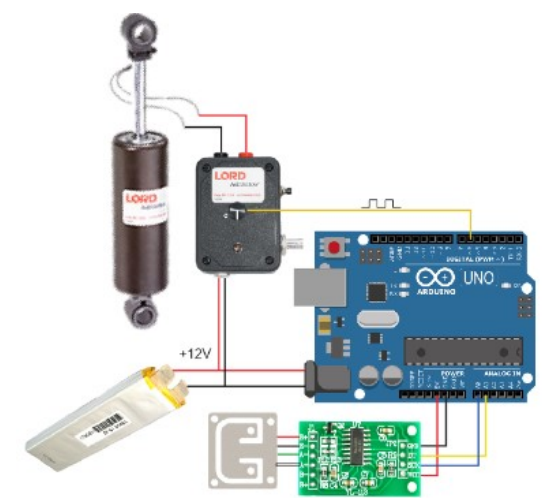

Fig. 5. Electronic connection diagram

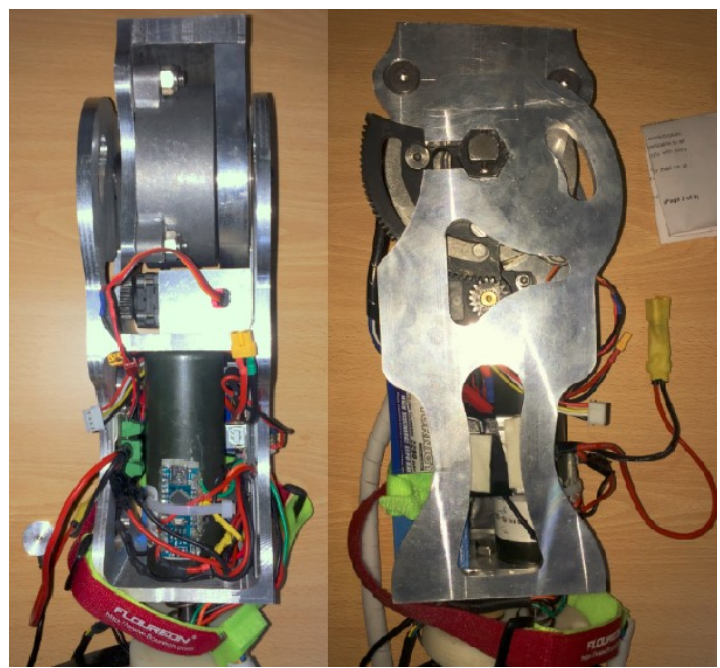

Fig. 6. Leg prototype

\section{Test and Results}

To validate the damper design several tests were performed, the first test was conducted by using load sensor, which records the load on the leg in function of time, this time is equal to the damping time during the gait cycle human, and its results are shown in figure 7.

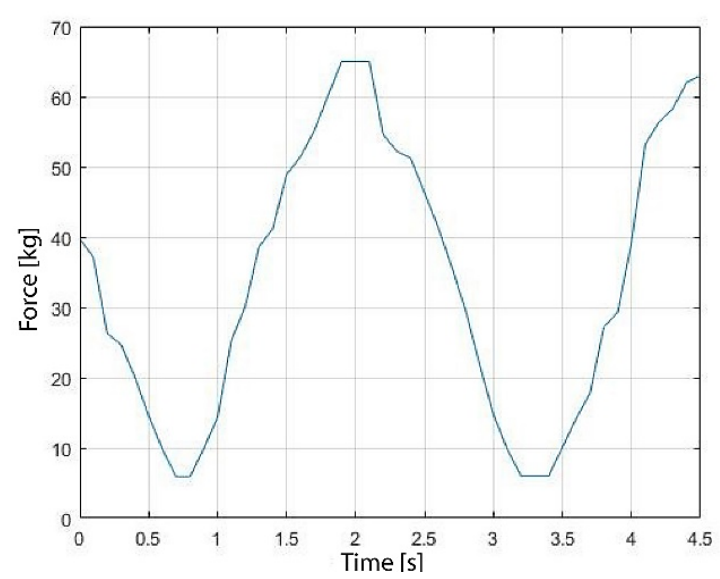

Fig. 7. Force vs. Damping time during the human gait cycle 
The second test was performed in a "Dyno-Shock" system that subjects the MR damper to expansion and compression continuously, with a current of $0 \mathrm{~A}$, magnetic field of $0 \mathrm{~T}$ and frequency of $1 \mathrm{~Hz}$, the test results are shown in figure 8, from which it can be seen that the maximum load during the expansion is $102 \mathrm{~kg}$.

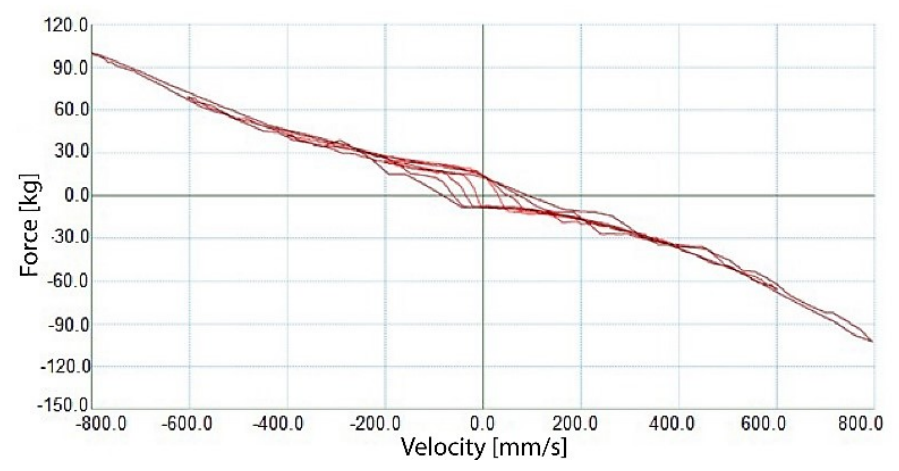

Fig.8. Force vs. Velocity at $0 \mathrm{~A}$

In a third test, similar to the previous one, with a current of $1.8 \mathrm{~A}$, magnetic field of $600 \mathrm{mT}$ and frequency of $1 \mathrm{~Hz}$, the results of the test are shown in Figure 9, from which it can be seen that the maximum load during the expansion is $250 \mathrm{~kg}$ which is equivalent to $2450 \mathrm{~N}$.

Through the calculations, it was established that the necessary force for the damping is of $2059 \mathrm{~N}$ with a current of $1.8 \mathrm{~A}$, and a magnetic field of $600 \mathrm{mT}$, but the tests showed that the shock absorber can reach higher values, so that the damper fulfills with the design requirements.

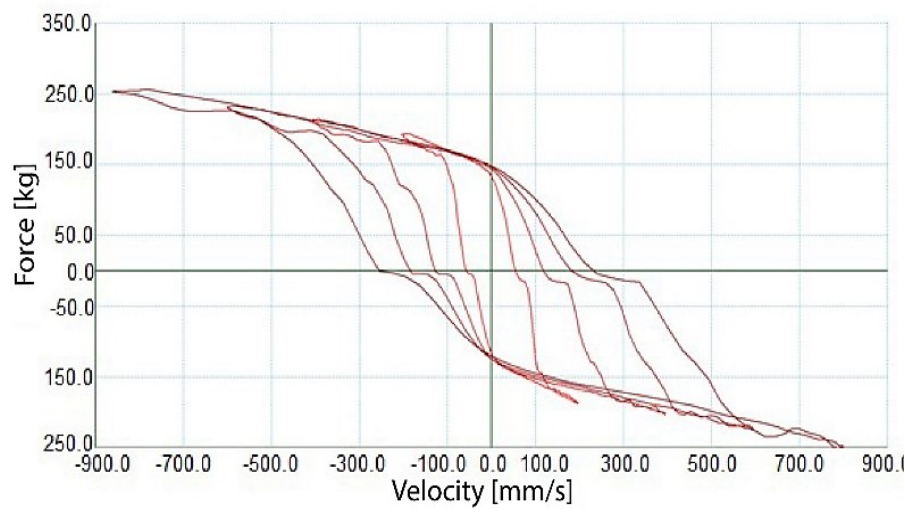

Fig.9. Force vs. Velocity at $1.8 \mathrm{~A}$

\section{Conclusions}

- The maximum force required to obtain a suitable damping is $2059.26 \mathrm{~N}$, which is achieved with an input current to the coil of 1.8 A creating a magnetic field of $600 \mathrm{mT}$.

- The minimum force provided by the prototype is $1000 \mathrm{~N}$, equivalent to $102 \mathrm{~kg}$, with a current magnetic field of $0 \mathrm{~T}$, this force is sufficient to maintain the weight of the user at rest, as well as providing energy savings that can lengthen the time of use of the prosthesis.
- In the results for expansion and compression tests, these show that as the current value increases, the damping force increases and the displacement of the piston decreases. The damping force is low for zero current and increases gradually as the current increases.

\section{References}

[1] Fragassa C., Berardi L., Balsamini G. Magnetorheological fluid devices: an advanced solution for active control. Faculty of Mechanical Engineering, (2016) 333-339.

[2] García J., Rodríguez C. Diseño de una Prótesis Transtibial Amortiguada. México DF. México: Instituto Politécnico Nacional, (2012).

[3] Gonzales M., \& al, e. Amputación de extremidad inferior y discapacidad. Prótesis y Rehabilitación. Barcelona: Masson, (2005).

[4] Victor Ragusilaa, M. Reza Emami. Mechatronics by analogy and application to legged locomotion, Mechatronics, Inform. Process. 000(2016) 1-19.

[5] Michael R Tucker, Jeremy Olivier, Anna Pagel, Hannes Bleuler, Mohamed Bouri, Olivier Lambercy, José del R Millán, Robert Riener, Heike Vallery, Roger Gassert. Control strategies for active lower extremity prosthetics and orthotics: a review. Journal of NeuroEngineering and Rehabilitation, 12(1)(2015).

[6] Andrés G, Luis C, Diseño y construcción de protesis de miembro inferior monitoreado desde un computador personal, (2015).

[7] Au, Samuel K., Weber J., Herr H. Powered ankle--foot prosthesis improves walking metabolic economy. IEEE Transactions on Robotics, 25(1)(2009), 51-66.

[8] Martinez V., E. Mooney L., Elliott G., Herr H. Antagonistic active knee prosthesis. A metabolic cost of walking comparison with a variable-damping prosthetic knee. In Engineering in Medicine and Biology Society. (2011) 8519-8522.

[9] Farris R. J., Quintero H. A., Murray S. A., Ha K. H., Hartigan C., Goldfarb M. A preliminary assessment of legged mobility provided by a lower limb exoskeleton for persons with paraplegia. IEEE Transactions on neural systems and rehabilitation engineering, 22(3)(2014) 482-490.

[10] Zhan H, Liao C, Chen W, Huang S, A magnetic design method of MR fluid dampers an FEM analysis on magnetic saturation, (2006),

[11] H.M., L., G., S., C., G., \& C., K. Reliable Plate-Plate MRF Magneto-Rheometry Based on Validated Radial Magnetic Flux Density Profile Simulations. Rheo, (2008).

[12] Lema, V. (Julio de 2013). Comparación estadística de medidas antropométricas entre mestizos,afroecuatorianos e indígenas del Ecuador.,http://repositorio.usfq.edu.ec/bitstream/23000/2631/1/1 07724.pdf

[13] Antonio, J., \& Mas, D. (2015). Recuperado el 07 de Agosto de 2017,http://www.ergonautas.upv.es/metodos/biomecanica/biome canica-ayuda.php

[14] Rajtukova, V, Michaliková, M, Bednarciková, L, Balogová, A, Zicak, Biomechanics of lower limb prostheses, 2014.

[15] Yang G., Spencer Jr., B., Carlson J., Sain M.. Large-scale MR fluid dampers: Modeling and dynamic performance considerations, ELSEVIER. (2002) 309-323.

[16] Richard G. Budynas, kate Gleason, Shigley's mechanical engineering design- Tenth editionMexico: McGraw-Hill., 2014.

[17] R. Mott, Resistencia de materiales, Mexico: Pearson educación, S.A., 2009.

[18]F. D. Goncalves, M. Ahmadiam y J. D. Carlson, Investigating the magnetoreological effect at high Flow velocities, 2006. 